\title{
MECHANICAL AND FRACTURE PROPERTIES OF GLASS VINYLESTER INTERFACES
}

\author{
J.E. Yetman ${ }^{\mathrm{a}, *}$, A.J. Sobey ${ }^{\mathrm{a}}$, J.I.R. Blake ${ }^{\mathrm{a}}$, R.A. Shenoi ${ }^{\mathrm{a}}$ \\ ${ }^{a}$ Fluid Structure Interactions, University of Southampton, University Rd, Southampton \\ SO17 1BJ, England, UK
}

\begin{abstract}
Glass fibres are a popular choice of material for large structural applications. However, a consistent set of mechanical and interface properties for glass vinylester woven roving is missing from the literature. To predict failure more accurately this paper fully characterises glass composite material, including developing a model for the non-linearity of the woven roving in tension and shear. The mode I and mode II fracture properties for co-cured and post-cured joints are assessed and compared providing a full characterisation of typical materials with a complete data set for both co-cured interfaces, typical of mid-laminate debonds, and post-cured interfaces, typical of sub-component joints.
\end{abstract}

Keywords: Fracture, Material Properties, Delamination, GFRP

\section{Introduction}

Composites are used extensively in engineering with the majority of industrial applications being made of glass, as they provide a balance between performance and cost. These are often paired with vinylester resins which provide higher fracture strains than typical polyesters and hence produce composites with superior mechanical properties, impact resistance and fatigue life. For large engineering structures composite joints between plates, stiffeners and other sub

\footnotetext{
* Corresponding author

Email address: J.E.Yetman@Soton.ac.uk (J.E. Yetman)
} 
components are often post-cured due to the scale of the production process. Typical interfaces contain a chopped strand mat (CSM) layer to provide a path of least resistance for the resin infusion between the stiffener and the plate. Debonding of subcomponent parts is a common failure mode of these types of structures however the characterisation of these typical post-cured interfaces is not well documented.

Many authors have already investigated fracture properties for heavy weight woven co-cured joints however, the associated mechanical characterisation is lacking. Mouritz et al. [1] conducted mode I tests on post-cured alternating plies of plain woven roving and chopped strand mat, quantifying its effect on the interface but the results for this data are unclear. Aside from this work chopped strand mat fracture toughness properties are not documented in the literature for mode I and not investigated for mode II crack opening at all.

Due to the importance of fracture in failure of composites a number of authors are characterising these properties for different materials, Katsiropoulos et al. [2], Campilho et al. [3] and Wang et al. [4]. Furthermore authors have investigated the effect of stiffener skin debonding for co-cured and post-cured manufacture, Yap [5], Meeks et al. [6], Orifici et al. [7] and Yetman et al. [8], but have neglected the CSM layer which is present in stiffener-plate joints.

When modelling such structural interfaces a complete data set is required, drawing upon multiple and non similar sources can lead to significant errors due to the variation in manufacturing methods, fibre volume fraction, weave structure, fabric weight and sample thickness.

This paper therefore presents a full data set of mechanical characterisation tests along with the interface properties in mode I and II for co-cured and postcured samples. The effect of the post-cured layer is quantified and compared for both mode I and mode II. Bi-linear models for tension and shear are proposed for woven roving materials and guidance is given on performing these tests for woven roving materials. 


\section{Mechanical Characterisation}

The material considered is a Scott Bader Crystic Resin VE679-03PA with a balanced $600 \mathrm{gsm}$ woven roving typical of resin infusion based builds. The resin is a pre-accelerated, DCPD modified, vinylester resin, developed for use as an infusion resin. As the fabric is balanced the material is tested in a single direction parallel to the fibre. Test standards are not available for woven fabrics therefore uni-directional or multi-direction standards are used as a guide. Tensile, compressive and shear tests are conducted.

\subsection{Tensile}

Coupons were tested under tension to BS ISO EN 527-4:2009. Type 3 coupons are used as defined in the standard: $250 \mathrm{~mm}$ in length and $25 \mathrm{~mm}$ in width with $150 \mathrm{~mm}$ between the end tabs which are $50 \mathrm{~mm}$ in length; two thickness are investigated, $7.5 \mathrm{~mm}$ and $5 \mathrm{~mm}$. Two strain gauges are mounted to the front surface one parallel and one perpendicular to the loading direction.

The in-plane stress-strain curves for the two sample thicknesses are shown in figure 1. There is an initial hardening phase, as described by Cox [9] and Zhou and Davies [10], which is attributed to 'inelastic' straightening of the crimped in-plane tows which was visually observed during the experiments. This results in a bi-linear stress-strain relationship for the $5 \mathrm{~mm}$ samples and to a lesser extent for the $7.5 \mathrm{~mm}$ samples. The initial and final stiffness for the $5 \mathrm{~mm}$ and $7.5 \mathrm{~mm}$ samples are shown in table 1 . The coefficient of variation $(\mathrm{CoV})$ for each value is low, with a maximum of $6.68 \%$, giving good confidence in the results.

\subsection{Compression}

Compressive coupons are performed to BS ISO EN 14126:1999. Coupon type B1 is used with $110 \mathrm{~mm}$ length, $5 \mathrm{~mm}$ thickness, $10 \mathrm{~mm}$ width and $10 \mathrm{~mm}$ between the end tabs of $50 \mathrm{~mm}$ in length. $2 \mathrm{~mm}$ end tabs are manufactured from $\pm 45^{\circ}$ biax aligned with the fabric $0^{\circ}$ direction with the load direction. It was 
not possible to machine the tabbing flat however little deviation was observed in the thickness of both the tabbing and test laminates. Load, displacement, and strain gauge readings were recorded continuously until the specimen fractured.

Strain gauges were mounted on the front and back surfaces of the specimen and aligned with the loading direction, the average strain is calculated from both surfaces. It is noted that the strain on the front and back gauges remained negative through the tests indicating that global buckling of the specimen did not take place in any of the samples. Samples where shear failure occured at the tabbing-coupon interface were discarded. The results are summarised in table 1. The Young's modulus and compressive strength have a coefficient of variation of $4.27 \%$ and $8.46 \%$ respectively showing low variation of the results and good confidence in repeatability for the tests.

\subsection{Shear}

Shear tests are performed to BS ISO 14129:1997 with the exception of the specimen thickness where a sample of $5 \mathrm{~mm}$ was tested to ensure the manufacturing method and fibre volume fraction were similar to the other characterisation tests. Panels are manufactured at $45^{\circ}$ to the loading direction with coupons of length $250 \mathrm{~mm}$, $5 \mathrm{~mm}$ thickness and $25 \mathrm{~mm}$ width. Strain is assessed by strain gauges parallel to and perpendicular to the loading direction. It is clear the test does not represent a pure shear mode however it does provide the in-plane shear stress to strain relationship required for an anisotropic stiffness matrix.

The shear stress strain relationship is shown in figure 2 where the relationship is initially linear up to a shear strain of approximately 0.002 followed by a gradual curve. This non-linear behaviour is due to matrix yielding which is attributed to the 'scissoring' action of the fibres. A second linear region is observed at a shear strain greater than 0.013. Final failure is observed in the load deflection curve as the fibres straighten in the loading direction. The inplane shear strength is shown in table 1 averaged from the 5 peak loads and 
is calculated at $57.9 \mathrm{MPa}$ with a coefficient of variation of $2.54 \%$ showing low variation.

The shear stress strain relationship may be approximated by a bi-linear approach. However, an initially elliptical relationship followed by a linear relationship provides an improved fit:

$$
\begin{gathered}
y=\sqrt{48.9^{2}\left(1-\frac{(x-0.02)^{2}}{0.204^{2}}\right)}-10 x<0.015 \\
y=400 x+31.5 x \geq 0.015
\end{gathered}
$$

\subsection{Flexural Modulus}

The flexural modulus was tested to BS ISO 14125:1998. 6 samples were tested under three point bending with a coupon width, b, of $15 \mathrm{~mm}$, and a thickness, $\mathrm{h}$, of $5 \mathrm{~mm}$; the distance between the outer rollers, $\mathrm{L}$, is $64.5 \mathrm{~mm}$. The flexural modulus is calculated between a surface strain of 0.005 and 0.0025 as recommended in the standard. The beam was tested until failure which was observed on the upper surface adjacent to the roller. The average flexural modulus is $22634 \mathrm{MPa}$ with a low coefficient of variation of $1.8 \%$. There is a non-linearity exhibited which initiates at roller displacements between $0.7 \mathrm{~mm}$ and $1.4 \mathrm{~mm}$. It is suggested that this non-linearity in bending is associated with the straightening of the fibres in tension as presented in the tensile tests.

\section{Fracture Properties}

Mode I DCB and mode II ENF tests are conducted for co-cured samples illustrating a delamination and for post-cured samples which contain a chopped strand mat, CSM, layer at the sub-laminate interface. Post-cured samples are manufactured by infusing the laminate in 2 hits with the first $2.5 \mathrm{~mm}$ sublaminate initially infused and the teflon layer, chopped strand mat and woven roving plies post-cured onto the first sublaminate. 


\subsection{Mode I Strain Energy Release Rate Co-Cured}

The mode I critical strain energy release rate is assessed by DCB tests conducted using BS ISO EN 7991:2001. The reference states that a minimum of 4 specimens are required. The coupon dimensions are not specified in the standard and are set to represent the full scale structure with a mid laminate crack; $2.5 \mathrm{~mm}$ arm thickness for a total laminate thickness of $5 \mathrm{~mm}$. The initial crack length is approximately $30 \mathrm{~mm}$, the coupon width is $25 \mathrm{~mm}$ and the coupon length $150 \mathrm{~mm}$. The sides of the specimen are spray painted white and marked at every $1 \mathrm{~mm}$ from the end of the crack tip for $10 \mathrm{~mm}$ and then every $5 \mathrm{~mm}$ for a total distance of $65 \mathrm{~mm}$ from the crack tip as defined by the standard. A test block is adhered to the ends of the specimen, using araldite 2014, ensuring both the center of the hole for loading and the front of the load block are aligned on the upper and lower side.

The width and thickness are measured at three locations along the length, averaged and the initial crack length is measured on each sample prior to testing. Initial tests are conducted to create a pre-crack; the samples are loaded at a rate of $1 \mathrm{~mm} / \mathrm{min}$ until the crack is seen to propagate and a loaded drop is observed. The specimens are then unloaded fully at a rate of $5 \mathrm{~mm} / \mathrm{min}$. The crack lengths are measured on both sides of the specimen to ensure the crack has propagated perpendicular to the coupon length. The sample is loaded again monitoring the crack length using a DSLR camera until the crack reaches a length of $65 \mathrm{~mm}$ from the initial crack tip. The load deflection response is synchronised with the crack length data observed visually, the sample is then unloaded at a rate of $5 \mathrm{~mm} / \mathrm{min}$.

BS ISO EN 7991:2001 describes three approaches for determining the initial critical strain energy release rate: the point of non-linearity, 'NL', defined where the load deflection curve deviates from the initial compliance line, the first point at which the crack is observed to propagate, 'VIS', and 'MAX/5\%' determined at the minimum of either the maximum load or the change in compliance of 
$5 \%$. The initial crack initiation values are similar between theese methods, summarised in table 2. For each test there is an initial load drop followed by a further increase in load; the non-linear method is used to determine the initial critical strain energy release rate which corresponds to this initial peak in load and therefore gives the truest sense of the crack initiation load for this case with an average of $0.354 \mathrm{KJ} / \mathrm{m}^{2}$ and a coefficient variation of $37.5 \%$. The inherent variation of the weave structure contributes to the variation in the critical strain energy release rate as well as the degree of misalignment between the upper and lower weave structure relative to the teflon layer. The coefficient of variation is reduced significantly for the visible crack initiation, VIS, to $21.7 \%$. The non 'visible' crack growth which causes a non-linearity in the load deflection curve is small in comparison to the tow width. Due to the slip-stick nature of the crack growth it is likely that crack growth is more noticable during the period of unstable growth with the crack arresting at the face of the next transverse tow. Therefore, there is less variability in the visible crack growth as it is less dependent on the variation in the relative teflon and weave location. For all tests the $5 \%$ change in compliance occurs prior to the maximum load. The $5 \%$ change in compliance gives a standardised approach to characterising the nonlinear response however the initial load drop is followed by a further increase in load and the critical load is sensitive to the specified compliance change, in this case $5 \%$, resulting in a high degree of variation. Therefore the visibility method is recommended for this case.

Figure 3 shows the crack propagation of a typical sample. The load line is illustrated along with the tow width which is determined visually and measured at $4.5 \mathrm{~mm}$. Crack growth is observed using these images synchronised to the corresponding load and extension. It is observed that cracks form under the cut tows which makes the determination of the crack length difficult to identify. The crack develops on the upper and lower side of the cut tow resulting in a sharp increase in the perceived critical strain energy release rate due to the increase in 
the surface area of the developed fracture surface. Examination of the fracture surface shows the cut tows are present only on one side of the specimen for the majority of the specimens.

A typical load deflection curve shown in figure 4 illustrates the slip-stick nature of the crack propagation. Ebeling et al. [11] showed that the crack growth in woven fabric composites is dominated by fibre/matrix interface debonding following the undulating pattern of the yarns. To post-process this slip-stick propagation Mouritz et al. [12] determined the critical strain energy release rate from pre-determined values of the crack growth. However, Davies and Moore [13] discussed the problem in characterising the delamination resistance of unidirectional glass/Nylon-66 and defined key values which are illustrated in figure 4. The grey areas correspond to where the crack tip is in the region of the cut tow. Increased peaks are observed as the crack front passes the tow and the tow bridges behind the crack tip, these increased instability points are marked in yellow. Instability points that correspond to no fibre bridging are marked in black and the arrest points are marked in red. For each specimen the three instability points and arrest points are calculated with respect to the bridging cut tows. Although there is significant variation across the values between specimens there is no obvious resistance curve, therefore all data points are included to ascertain the crack propagation values. The results for the strain energy release rate for the instability, bridging instability and arrest points are shown for the 4 samples tested in table 2 where a minimum of 3 points are averaged for each value. It is noted that coupon $4 a_{-} 7$ does not have an instability point as the coupon is cut to have a cut tow on alternate sides and therefore bridging occurs during all of the crack growth. The bridging of the cut tows provides an artificial increase in resistance that would not be present in a pure mode I crack growth therefore the instability point without bridging should be used for future modelling to provide a conservative result and to eliminate the increase in resistance of the bridging tows. 
There is an inherent variability in the alignment of the fabric and relative location of the adjacent plies. This variability is particularly apparent for interlaminar properties where the local roughness and variation in alignment and the weave structure lead to resin-rich areas which allow larger plastic yield zones to develop ahead of the crack tip [14, 11]. Naik et al. [15] show there are other natural variations which cause the properties to vary between samples, which are particularly prominant for interlaminar properties.

Specimen width has been shown not to affect the fracture toughness of unidirectional composites [16] however, it is evident from the study here that it is a critical parameter for woven composites. It is suggested that the result could be improved by eliminating the bridged tows by defining the edges of the specimen using teflon strips to prevent adhesion of the cut tows. E-glass vinylester mode I results from other authors are presented in table 5. There is significant variation across the samples and variation in the manufacturing and test procedures although the results presented here have similar values.

\subsection{Mode I Strain Energy Release Rate Post-Cured}

The same three methods are used to calculate the crack initiation values with the results shown in table 3 , with a $10.5 \%$ variation between the methods. Multiple load drops occur in these post-cured samples prior to the peak load resulting in a change in stiffness and prior to the crack becoming visible. The least variation is observed for the non-linear method in this case.

For the post-cured samples a resistance curve is evident with an increase in strain energy release rate with crack length over the first $15-25 \mathrm{~mm}$. Samples 6a2-6a5 exhibit a plataeu in the strain energy release rate for a crack length of $60 \mathrm{~mm}$ and greater. Good agreement is shown between samples 6a3-6a5 whilst higher strain energy release rate values are shown for samples 6a1-6a2. The initial linear increase is more pronounced for samples 6a1 with an increase in strain energy release rate for a crack growth of up to $30 \mathrm{~mm}$. 
Unlike the co-cured samples a uniform slip-stick behaviour is not shown in these samples due to the irregular interface. The data is therefore averaged in the plateau region for a crack length of greater than $60 \mathrm{~mm}$ and shown in table 3. The results show there is similar variation about the average for each sample in the region of 11.5-17.3\% however the coefficient of variation across the full data set is greater at $20.7 \%$. This is largely explained by the difference between the samples in the relative alignment of chopped fibres parallel to the crack propagation direction introduced by the CSM layer. Fibres aligned to the loading direction provide a greater force, acting over a longer length and acting in parallel with more fibres, resulting in higher critical strain energy release rates. Fibre bridging is apparent in all samples and occurs for approximately $30 \mathrm{~mm}$ behind the crack tip. However, it is clear from the observations during the test that samples 6a1 and 6a2 have a higher degree of alignment in the CSM layer to the loading direction. Sample 6a1 shows that a number of fibres bridge the sub-laminates ahead of the teflon layer and provide a resistive force prior to breaking at a visible crack length of $85-90 \mathrm{~mm}$.

\subsection{Mode II Strain Energy Release Rate Co-Cured}

The mode II strain energy release rate is calculated using the end notch flexure technique and ASTM D7905/D7905M-15. The experimental setup and dimensions are shown in figure 5 . The specimen roller radius used was $10.0 \mathrm{~mm}$ for all three rollers, the distance between rollers, length, is $50 \mathrm{~mm}$, width, $20 \mathrm{~mm}$, and thicknesses, $5 \mathrm{~mm}$, are measured from each specimen. A Teflon insert is used for the pre-crack as used in the DCB tests.

The edges of the specimen were spray painted white to determine the crack tip and crack growth. The compliance method was used as outlined in the standard. The compliance is tested for a $20 \mathrm{~mm}, 30 \mathrm{~mm}$ and $40 \mathrm{~mm}$ crack length and a relationship between the specimen compliance and crack length is determined. The specimen is then loaded at a crack length of $30 \mathrm{~mm}$ until the crack ad- 
vances whilst monitoring the load and displacement. The unloading compliance is then used to determine the crack advancement for future tests. The peak load is used to establish the critical strain energy release rate. The process is then repeated for the pre-cracked sample to re-establish the compliance relationship and determine the peak load for further crack advancement.

The results are tabulated in table 4 for the non pre-cracked (NPC) and precracked (PC) samples. The non pre-cracked samples showed an average critical strain energy release rate of 0.761 with a coefficient of variation of $11.7 \%$ whereas the pre-cracked samples increased by $30 \%$ to 0.936 with a coefficient of variation of $5.3 \%$. The coefficients of variation are considered to be low for both NPC and $\mathrm{PC}$ values.

The results from other authors for e-glass vinylester mode II tests are presented in table 5 and compared to the current results showing there is significant variation across the samples and variation in the manufacturing and test procedures. The results presented here for the mode II crack initiation are in the region of those reported by other authors however the propagation results are significantly lower. The variation observed between the crack propagation fracture toughness assessed here and the comparable literature may be attributed to the level of compaction and degree of mechanical interlocking present in the tested samples or could be one of the many differing factors between the tests; manufacturing method, fibre volume fraction or differences in the mechanical properties of the component materials. However good repeatability is seen in the test results giving confidence for this specific configuration.

\subsection{Mode II Strain Energy Release Rate Post-Cured}

The mode II experiments described in the previous section are repeated for a post-cured specimen containing a layer of chopped strand mat at the cracked interface. The results are presented for these specimens in table 4. The non pre-cracked samples showed an average critical strain energy release rate of 
1.12 with a coefficient of variation of $12.6 \%$ whereas the pre-cracked samples increased by $42 \%$ to 1.59 with a similar coefficient of variation of $12.3 \%$. Both critical strain energy release rates are increased in the post-cured specimen relative to the co-cured specimen by $47.2 \%$ and $70.0 \%$ for the NPC and PC specimens respectively. For both the non pre-crack and pre-cracked specimen this is due to the introduction of the CSM which is likely to provide a path of least resistance for the resin during the infusion process. This results in a higher resin content at the interface between the sub-laminates and larger resin filled areas which allow larger plastic yield zones to develop ahead of the crack tip. The coefficient of variation is increased in the post-cured samples which is likely to be due to the variation in the chopped strand mat layer which provides a varied interface between the two sub-laminates.

\section{Conclusions}

Many large structures are manufactued using woven roven glass fibres but a consistent fracture characterisation of these materials is missing from the literature. In this paper the material is characterised in tension, compression, shear and flexure to provide a full set of the necessary characterisation data for a typical lay-up. The non-linearity of the woven roving in tension and shear is characterised. Mode I and mode II fracture properties are compared for co-cured and post-cured joints in heavy weight glass vinylester woven roving typical of the marine industry. Specimen width has been shown not to affect the fracture toughness of unidirectional composites however it is shown here that it is a critical parameter for woven composite and this requires further investigation. Post-curing is shown to have a considerable effect on the fracture properties where the CSM mat is shown to increase the mode I critical strain energy release rate by $17.4 \%$ and the mode II critical strain energy release rate by $70 \%$. 


\section{Acknowledgements}

The authors would like to thank the UK Ministry of Defence and Lloyd's Register EMEA for their continued support and without whom this research would not have been possible.

\section{References}

[1] A. P. Mouritz, C. Baini, and I. Herszberg. Mode I interlaminar fracture toughness properties of advanced textile fibreglass composites. Composites Part A: Applied Science and Technology, 30:859-870, 1999.

[2] C. Katsiropoulos, A. Chamos, K. Tserpes, and S. Pantelakis. Fracture toughness and shear behavior of composite bonded joints based on a novel aerospace adhesive. Composites Part B: Engineering, vol. 43:240-248, 2012.

[3] R. Campilho, D. Moura, D. Goncalves, J. da Silva, M. Banea, and L. da Silva. Fracture toughness determination of adhesive and co-cured joints in natural fibre composites. Composites Part B: Engineering, vol. 50:120-126, 2013.

[4] F. Wang, Z. Shao, and Y. Wu. Mode ii interlaminar fracture properties of moso bamboo. Composites Part B: Engineering, vol. 44:242-247, 2013.

[5] J. Yap. The analysis of skin-to-stiffener debonding in composite aerospace structures. Composite Structures, 57(1-4):425-435, jul 2002.

[6] C. Meeks, E. Greenhalgh, and B. Falzon. Stiffener debonding mechanisms in post-buckled CFRP aerospace panels. Composites Part A: Applied Science and Manufacturing, 36(7):934-946, jul 2005.

[7] A. C. Orifici, I. Dezaratealberdi, R. Thomson, and J. Bayandor. Compression and post-buckling damage growth and collapse analysis of flat 
composite stiffened panels. Composites Science and Technology, 68(15-16): $3150-3160$, dec 2008.

[8] J. E. Yetman, A. J. Sobey, J. I. R. Blake, and R. A. Shenoi. Investigation into skin stiffener debonding of top-hat stiffened composite structures. Composite Structures, 132:1168-1181, 2015.

[9] B. N. Cox. On the tensile composites failure of 3D wovencomposites . Composites Part A: Applied Science and Manufacturing, pages 447-458, 1996.

[10] G. Zhou and G. Davies. Characterization of thick glass woven roving/polyester laminates: 1. Tension, compression and shear. Composites, 26(8):579-586, aug 1995.

[11] T. Ebeling, A. Hiltner, E. Baer, I. M. Fraser, and M. L. Orton. Delamination Failure of a Woven Glass Fiber Composite. Journal of Composite Materials, 31(13):1318-1333, jul 1997.

[12] A. P. Mouritz, C. Baini, and I. Herszberg. Mode I interlaminar fracture toughness properties of advanced textile fibreglass composites. Composites Part A: Applied Science and Manufacturing, 30(7):859-870, 1999.

[13] P. Davies and D. Moore. Glass/Nylon-6.6 composites: delamination resistance testing. Composites Science and Technology, 38:211-227, 1990.

[14] B. Briscoe, R. Court, and D. Williams. The effects of fabric weave and surface texture on the interlaminar fracture toughness of aramid/epoxy laminates. Composites Science and Technology, 47(3):261-270, jan 1993.

[15] N. K. Naik, K. S. Reddy, S. Meduri, N. B. Raju, P. D. Prasad, S. N. M. Azad, P. A. Ogde, and B. C. K. Reddy. Interlaminar fracture characterization for plain weave fabric composites. Journal of Materials Science, 37 (14):2983-2987, 2002. 
[16] W. Johnson, J. Masters, T. O’Brien, T. O’Brien, and R. Martin. Round Robin Testing for Mode I Interlaminar Fracture Toughness of Composite Materials. Journal of Composites Technology and Research, 15(4):269, 1993.

[17] K. N. Shivakumar. Carbon/Vinyl Ester Composites for Enhanced Performance in Marine Applications. Journal of Reinforced Plastics and Composites, 25(10):1101-1116, may 2006.

[18] S. P. Blake, K. a. Berube, and R. a. Lopez-Anido. Interlaminar fracture toughness of woven E-glass fabric composites. Journal of Composite Materials, 46(13):1583-1592, oct 2011.

[19] F. Dharmawan, G. Simpson, I. Herszberg, and S. John. Mixed mode fracture toughness of GFRP composites. Composite Structures, 75(1-4):328338 , sep 2006.

[20] P. Compston. Comparison of Interlaminar Fracture Toughness in Unidirectional and Woven Roving Marine Composites. Applied Composite Materials, pages 189-206, 1998.

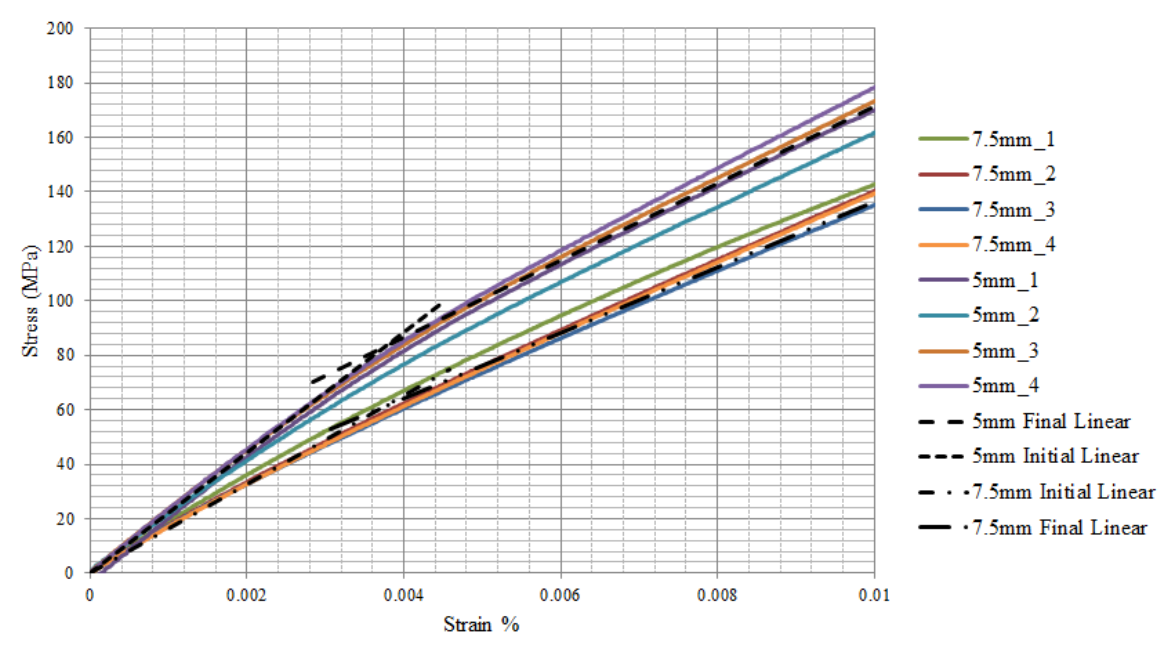

Figure 1: Tensile stress strain relationship of $5 \mathrm{~mm}$ and $7.5 \mathrm{~mm}$ coupons 


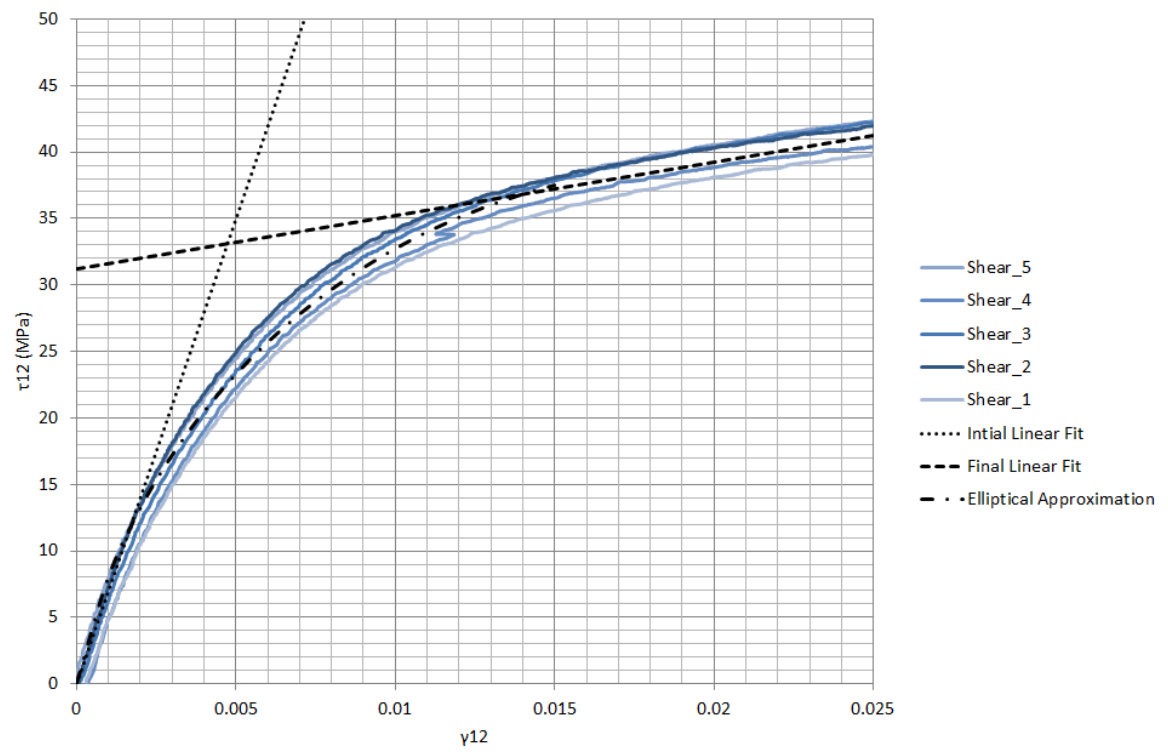

Figure 2: Shear stress against shear strain

Load Line

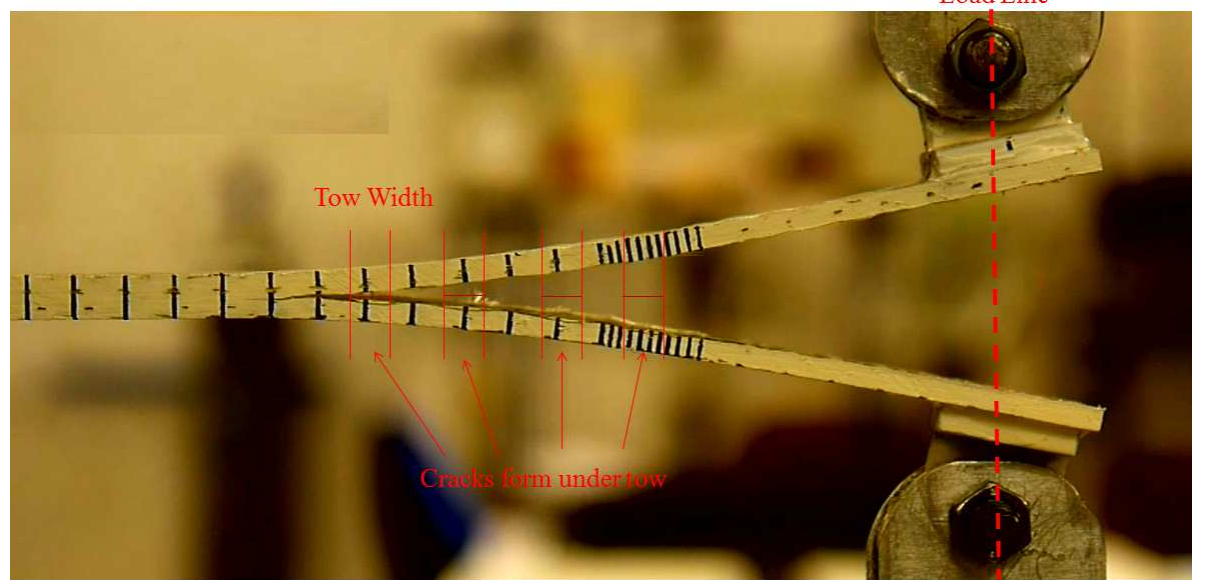

Figure 3: DCB test arrangement 


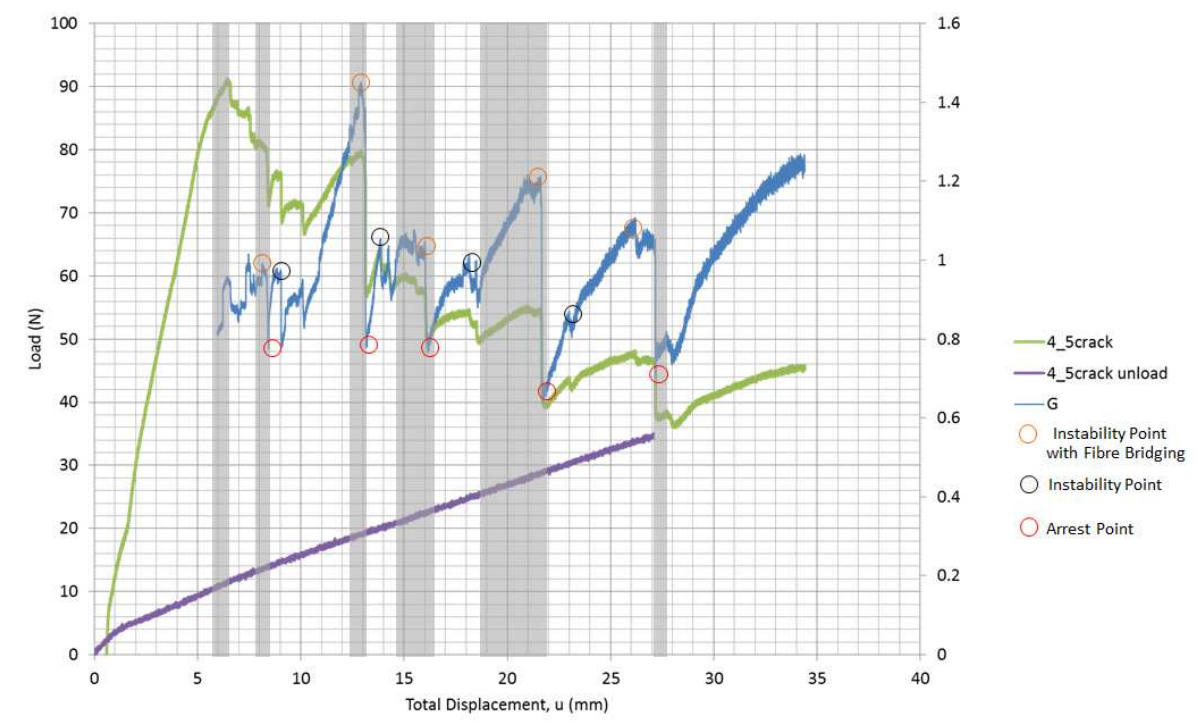

Figure 4: Load deflection response with calculated strain energy release rate

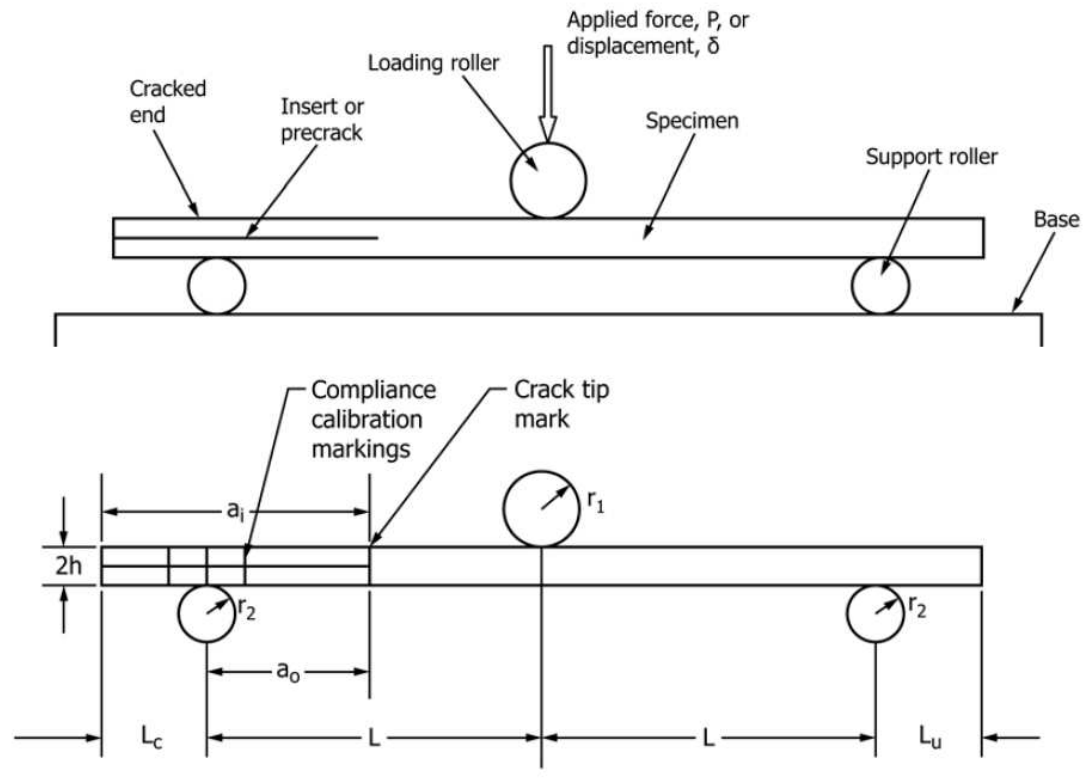

Figure 5: ENF experimental setup 
Table 1: Mechanical test results

\begin{tabular}{|c|c|c|c|}
\hline & $\begin{array}{c}\text { Number of } \\
\text { Specimens }\end{array}$ & Average (MPa) & CoV (\%) \\
\hline \hline Tensile 5mm initial slope & 4 & 22100 & 6.68 \\
\hline Tensile 5mm final slope & 4 & 14100 & 3.00 \\
\hline Tensile 7.5mm intial slope & 4 & 16300 & 4.94 \\
\hline Tensile 7.5mm final slope & 4 & 12000 & 2.61 \\
\hline Poisson's Ratio & 6 & .139 & 17.7 \\
\hline Compressive Modulus & 5 & 31240 & 4.27 \\
\hline Compressive Strength & 5 & 272.5 & 8.46 \\
\hline Shear Strength & 5 & $57.9 \mathrm{MPa}$ & 2.54 \\
\hline
\end{tabular}

Table 2: Strain energy release rates for co-cured crack initiation and propagation

\begin{tabular}{|c|c|c|c|c|c|c|}
\hline Specimen & NL & VIS & $\mathrm{MAX} / 5$ & Instability & Bridging & Arrest \\
\hline $\begin{array}{c}4 \mathrm{a}_{-} 5 \\
\left(K J / m^{2}\right)\end{array}$ & 0.506 & 0.494 & 0.507 & 0.984 & 1.18 & 0.734 \\
\hline $\begin{array}{c}4 \mathrm{a} \_6 \\
\left(K J / m^{2}\right)\end{array}$ & 0.419 & 0.453 & 0.635 & 0.920 & 1.06 & 0.744 \\
\hline $\begin{array}{c}4 \mathrm{a}_{-} 7 \\
\left(K J / m^{2}\right)\end{array}$ & 0.281 & 0.418 & 0.281 & - & 1.16 & 0.837 \\
\hline $\begin{array}{c}4 \mathrm{a}_{-} 8 \\
\left(K J / m^{2}\right) \\
\end{array}$ & 0.211 & 0.279 & 0.276 & 1.006 & 1.12 & 0.736 \\
\hline $\begin{array}{l}\text { Average } \\
\left(K J / m^{2}\right)\end{array}$ & 0.354 & 0.411 & 0.425 & 0.967 & 1.07 & 0.728 \\
\hline $\mathrm{CoV}(\%)$ & 37.5 & 21.7 & 41.6 & 14.5 & 14.0 & 12.4 \\
\hline
\end{tabular}


Table 3: Strain energy release rates for post-cured crack initiation and critical strain energy release rate

\begin{tabular}{|c|c|c|c|c|c|}
\hline $\begin{array}{c}\text { Specimen } \\
\text { ID }\end{array}$ & NL & VIS & MAX $/ 5$ & $\begin{array}{c}\text { Average } \\
\text { SERR }\end{array}$ & $\begin{array}{c}\text { SERR } \\
\text { CoV }(\%)\end{array}$ \\
\hline \hline $6 \mathrm{a} 1\left(K J / m^{2}\right)$ & 0.317 & 0.300 & 0.320 & 1.51 & 17.27 \\
\hline $6 \mathrm{a} 2\left(K J / m^{2}\right)$ & 0.200 & 0.192 & 0.176 & 1.39 & 11.5 \\
\hline $6 \mathrm{a} 3\left(K J / m^{2}\right)$ & 0.290 & 0.410 & 0.319 & 0.954 & 12.52 \\
\hline $6 \mathrm{a} 4\left(K J / m^{2}\right)$ & 0.308 & 0.370 & 0.379 & 0.865 & 12.66 \\
\hline $6 \mathrm{a} 5\left(K J / m^{2}\right)$ & 0.247 & 0.248 & 0.239 & 0.765 & 16.8 \\
\hline Average & 0.272 & 0.304 & 0.287 & 1.15 & 20.7 \\
\hline CoV $(\%)$ & 17.8 & 29.1 & 27.7 & - & - \\
\hline
\end{tabular}

Table 4: Co-cured and post-cured ENF experimental data

\begin{tabular}{|c|c|c|}
\hline Specimen ID & $G_{I I C}$ NPC & $G_{I I C}$ PC \\
\hline \hline \multicolumn{3}{|c|}{ Co-cured } \\
\hline 4a_4 & .782 & .957 \\
\hline 4a_5 & .688 & .995 \\
\hline 4a_6 & .695 & .886 \\
\hline 4a_7 & .879 & .904 \\
\hline 4a_9 & .720 & 1.08 \\
\hline Average & .761 & .936 \\
\hline CoV (\%) & $11.7 \%$ & $5.3 \%$ \\
\hline \multicolumn{3}{|c|}{ Post-cured } \\
\hline 7a_1 & 1.32 & 1.36 \\
\hline 7a_2 & 0.91 & 1.73 \\
\hline 7a_3 & 1.09 & 1.41 \\
\hline 7a_4 & 1.04 & 1.58 \\
\hline 7a_5 & 1.16 & 1.88 \\
\hline 7a_6 & 1.08 & 1.56 \\
\hline Average & 1.12 & 1.59 \\
\hline CoV (\%) & 12.6 & 12.3 \\
\hline
\end{tabular}


Table 5: Summary of experimentally determined material properties

\begin{tabular}{|c|c|c|c|c|c|c|}
\hline & Yetman & $\begin{array}{l}1 \text { (warp/ } \\
\text { weft) }\end{array}$ & 2 & 3 & 4 & 5 \\
\hline $\begin{array}{l}\text { Tensile Modulus } \\
(\mathrm{MPa})\end{array}$ & 22100 & $\begin{array}{l}29200 / \\
23900\end{array}$ & & & & \\
\hline Poisson's Ratio & .139 & $\begin{array}{c}0.16 / \\
0.14\end{array}$ & & & & \\
\hline $\begin{array}{l}\text { Compressive Modulus } \\
(\mathrm{MPa})\end{array}$ & 31240 & $\begin{array}{l}31900 / \\
26900\end{array}$ & & & & \\
\hline $\begin{array}{c}\text { Compressive Strength } \\
(\mathrm{MPa})\end{array}$ & 272.5 & $\begin{array}{l}363.4 / \\
336.4\end{array}$ & & & & \\
\hline Shear Modulus (GPa) & $.4-7$ & $\begin{array}{l}4.5 / \\
4.3\end{array}$ & & & & \\
\hline Shear Strength (MPa) & 57.9 & 47.3 & & & & \\
\hline $\begin{array}{l}\text { Flexural Modulus } \\
(\mathrm{MPa})\end{array}$ & 22634 & & & 24200 & & \\
\hline $\begin{array}{c}\text { Co-Cured Mode I } \\
\text { Strain Energy Release } \\
\text { Rate NPC }(\mathrm{kJ} / \mathrm{m} 2)\end{array}$ & .371 & & & 0.577 & 0.227 & 0.239 \\
\hline $\begin{array}{c}\text { Co-Cured Mode I } \\
\text { Strain Energy Release } \\
\text { Rate PC }(\mathrm{kJ} / \mathrm{m} 2)\end{array}$ & 0.967 & & 0.804 & 1.210 & 0.988 & 0.739 \\
\hline $\begin{array}{c}\text { Co-Cured Mode II } \\
\text { Strain Energy Release } \\
\text { Rate NPC }(\mathrm{kJ} / \mathrm{m} 2)\end{array}$ & 0.761 & & 0.627 & & 1.152 & 0.724 \\
\hline $\begin{array}{l}\text { Co-Cured Mode II } \\
\text { Strain Energy Release } \\
\text { Rate PC }(\mathrm{kJ} / \mathrm{m} 2)\end{array}$ & 0.936 & & & 4.550 & 5.461 & 4.102 \\
\hline $\begin{array}{l}\text { post-cured Mode I } \\
\text { Strain Energy Release } \\
\text { Rate NPC }(\mathrm{kJ} / \mathrm{m} 2)\end{array}$ & 0.345 & & & & & \\
\hline $\begin{array}{l}\text { post-cured Mode I } \\
\text { Strain Energy Release } \\
\text { Rate PC }(\mathrm{kJ} / \mathrm{m} 2)\end{array}$ & 1.15 & & & & & \\
\hline $\begin{array}{l}\text { post-cured Mode II } \\
\text { Strain Energy Release } \\
\text { Rate NPC }(\mathrm{kJ} / \mathrm{m} 2)\end{array}$ & 1.12 & & & & & \\
\hline $\begin{array}{l}\text { post-cured Mode II } \\
\text { Strain Energy Release } \\
\text { Rate PC }(\mathrm{kJ} / \mathrm{m} 2)\end{array}$ & 1.59 & & & & & \\
\hline
\end{tabular}

(1) Shivakumar [17] tested E-glass woven roving with a Dow Derakane 510A-40 brominated vinyl ester manufactured via VARTM

(2) Blake et al. [18] tested $800 \mathrm{gsm}$ woven E glass with a toughened Derakane 8084 matrix

(3) Dharmawan et al. [19] tested 800gsm woven E glass with a Derakane 411-350 matrix, data averaged if from multiple sources.

(4) Compston [20] tested Derakane 8084 using an E-glass woven 638gsm manufactured by hand lay up

(5)Compston [20] tested Derakane 411-45 using an E-glass woven 638gsm manufactured by hand lay up 